\title{
What is the normal value of the neutrophil-to-lymphocyte ratio?
}

\author{
Patrice Forget ${ }^{1,4^{*} \dagger}$, Céline Khalifa ${ }^{1 \dagger}$, Jean-Philippe Defour ${ }^{2}$, Dominique Latinne ${ }^{2}$, Marie-Cécile Van Pel ${ }^{3}$ \\ and Marc De Kock'
}

\begin{abstract}
Background: Neutrophil-to-lymphocyte ratio (NLR) has proven its prognostic value in cardiovascular diseases, infections, inflammatory diseases and in several types of cancers. However, no cut-off has been proposed on the basis of reference values coming from healthy population.

Methods: Routine blood samples were obtained ( $n=413)$ from workers (age: median 38, range: $21-66$ years) involved in a health care prevention program, to determine means, standard deviations (SDs), 95\% confidence intervals $(95 \% \mathrm{Cl})$, percentiles P2.5 and P97.5. A second independent sample of healthy volunteers is compared $(n=29)$.

Results: The mean NLR is 1.65 [ \pm 1.96 SD: 0.78-3.53] (95\% CI [0.75-0.81] and [3.40-3.66]). In the second cohort (healthy control), the NLR values are in the same range, whichever the used analyzer. No NLR assessed in the validation series is out of the proposed limits.
\end{abstract}

Conclusions: We have identified that the normal NLR values in an adult, non-geriatric, population in good health are between 0.78 and 3.53. These data will help to define the normal values of the NLR.

Keywords: Neutrophil-to-lymphocyte ratio, Cells count, Laboratory testing, Reference values

\section{Background}

Neutrophil-to-lymphocyte ratio (NLR) is a simple parameter to assess easily the inflammatory status of a subject. It has proven its usefulness in the stratification of mortality in major cardiac events [1,2], as a strong prognostic factor in several types of cancers [3-10], or as a predictor and a marker of inflammatory or infectious pathologies (such is pediatric appendicitis) and postoperative complications $[11,12]$.

However, which NLR value is correlated with a higher risk for these patients? Which cut-off value, for the NLR, will discriminate normal from abnormal results?

Different values of NLR, with different methods, in different populations (cancerous or not) are cited in the literature. And finally, no universal value is currently

\footnotetext{
*Correspondence: forgetpatrice@yahoo.fr

†Patrice Forget and Céline Khalifa contributed equally to this work

${ }^{4}$ Department of Anesthesiology and Perioperative Medicine, Vrije Universiteit Brussel (VUB), Universitair Ziekenhuis Brussel (UZ Brussel), Laarbeeklaan, 101, 1090 Brussels, Belgium

Full list of author information is available at the end of the article
}

available. Therefore, there is a need for reference values to progress in the use of this marker.

The aim of this study is to determine the limits of the values of the NLR that are observed in an adult, non-geriatric population, without any acute illness and/or chronic debilitating disease.

\section{Methods}

\section{Subjects and data collection}

With the agreement of the Ethical Committee (ref. 2014/451, Chairperson: Prof. Jean-Marie Maloteaux, av. Hippocrate, 55-14, 1200 Brussels), we performed the following analyses. Blood samples for routine control between October 2011 and 2012 were identified from 413 participants of the health care prevention program for workers. Considering the analysis as retrospective, given the fact that the samples were pre-collected and treated anonymously, the Ethical Committee gave a waiver for individual consent. Consequently, no written informed consent for participation in the study was obtained from participants. 
Median age was 38 years (range: $21-66$ years). Typically, these subjects were in good health, permitting a full time job without restriction, and without any active disease, including cancer and infectious disease and are representative of the population as a whole. Blood samples were obtained for routine hematologic control in workers potentially exposed to X-rays or any others ionizing radiation. Samples were treated anonymously, including sex and date of birth. No information was therefore available about habits (e.g. tobacco use) and possible comorbidities (e.g. obesity or vascular disease).

\section{Normal controls}

Our goal is to identify the higher boundary observed in a population in good health, but not excluding nondebilitating disease, tobacco use or oral contraception. Therefore, it would be important to compare the results to those obtained in a second, and independent, sample ( $n=29$ ) of normal controls, strictly selected on the basis of perfect health, coming from an historical cohort. This cohort was used during the process of the calibration of the blood analyser. The subjects in this second cohort were in the same range of age, but, after interrogation and examination, carefully selected on the basis of the absence of any chronic disease or substance/medications (abuse, including tobacco use).

\section{Samples analyses}

Anticoagulated whole blood from routine controls were processed on Sysmex XE2100 [TOA Medical Electronics, Kobe, Japan], Normal controls were analysed on Sysmex XN2000 (TOA Medical electronics Co, Kobe, Japan), Advia 2120 (Bayer Diagnostics, Tarritown, NY, USA), DXH800 (Beckman Coulter, Miami, FL USA), Cell-Dyn Sapphire (Abbott Diagnostics Santa Clara, CA, USA) for the determination of the complete blood cell counts and differential counts of leukocytes. The absolute neutrophil count was divided by the absolute lymphocyte count to calculate the NLR.

\section{Statistical analyses}

For the statistical analyses, laboratory parameters fit a log-normal distribution. Logarithmic conversion was therefore used for calculating means and 95\% confidence limits $(95 \% \mathrm{CI})$ are presented as arithmetic mean \pm 1.96 SD (with their 95\% CI). Power analysis shows that, to test the hypothesis that $<2.5 \%$ of the normal controls would be out of the proposed limits, 28 subjects are needed. It is the reason why we included 29 blood samples of the historical cohort for the external validation.

All the analyses were performed with STATISTICA (data analysis software system, version 7, Statsoft Inc. 2004, Tulsa).

\section{Results}

Results coming from the blood samples of the 413 subjects of the main cohort are presented in Table 1. Briefly, the mean NLR is 1.65 [ \pm 1.96 SD: $0.78-3.53]$ (95\% CI [0.75-0.81] and [3.40-3.66]). In the second cohort (healthy control), the NLR values are in the same range, whichever the used analyzer (Table 1). Consequently, no NLR assessed in the validation series is out of the proposed limits.

NLR sample stability over $48 \mathrm{~h}$ was assessed; there was no significant variation over this time period and the NLR was then considered stable.

\section{Discussion}

We show here that the NLR values, in a sample of 413 active subjects in good health, are between 0.78 and 3.58 . We confirm that no normal control (selected on the basis of the absence of any comorbidities and substance abuse, including tobacco) exceeded this range.

There are a lot of examples in the literature of the interest of the NLR as an independent prognostic factor of morbidity and mortality in several conditions, such as cancers and cardiovascular diseases. NLR is also useful in the prediction and the detection of inflammatory and infectious conditions, and their postoperative

Table 1 Neutrophil-to-lymphocyte ratios obtained in two cohort of subjects $(n=413$ and $n=29)$ on five blood analysers, expressed in mean, SD and lower/upper limits of the mean \pm 1.96 SD range (and their $95 \% \mathrm{CI}$ )

\begin{tabular}{|c|c|c|c|c|c|c|c|c|}
\hline & Mean & SD & Lower limit & $95 \% \mathrm{Cl}$ & & Upper limit & $95 \% \mathrm{Cl}$ & \\
\hline \multicolumn{9}{|c|}{ Initial cohort $(n=413)$} \\
\hline Sysmex XE2100 & 1.65 & 1.47 & 0.78 & 0.75 & 0.81 & 3.53 & 3.40 & 3.66 \\
\hline \multicolumn{9}{|c|}{ Control cohort $(n=29)$} \\
\hline Beckman DXH800 & 1.76 & 1.42 & 0.89 & 0.78 & 1.02 & 3.49 & 3.06 & 3.97 \\
\hline Siemens 2120i & 1.86 & 1.39 & 0.97 & 0.86 & 1.10 & 3.54 & 3.13 & 4.00 \\
\hline Abbott SAPHYR & 1.68 & 1.42 & 0.85 & 0.74 & 0.96 & 3.32 & 2.92 & 3.79 \\
\hline Sysmex XN2000 & 1.69 & 1.37 & 0.91 & 0.81 & 1.03 & 3.12 & 2.77 & 3.52 \\
\hline
\end{tabular}


complications $[11,12]$. Nevertheless, none of these studies based their cut-off on data coming from population in good health, and none on data coming from normal controls. Some of these studies chose their cut-off value on the basis of the median, higher quartile or values determined by the use of receiver-operating curves (to predict the occurrence of a condition, e.g. cancer recurrence of infection) [13-15].

In contrast with these studies, we found here limits based on a sample of an active adult population in good health.

This value can be used as a cut-off to differentiate patients that are in the range of a population in good health or not [16]. Can it be used in other populations that this from which this sample is coming? Age is certainly a limit, as we tested only adult, non-geriatric, subjects (between 21 and 66 years). Additionally, we did not have the complete documentation of substance use/ abuse, like tobacco or oral contraceptive. Ethnic group origins, sex and season of assessment have not been included in the analyses. However, in the sample of normal control, we see that the $95 \%$ CI permits to say that it is very improbable that normal controls will have a NLR value of 3.5. Nevertheless, it seems logical to interpret cautiously this type of parameter (like any other), in a clinical context to adjust the interpretation, even if based on data coming from a comparable population (Additional file 1).

\section{Conclusions}

We have identified that normal NLR values in an adult, non-geriatric, population in good health are between 0.78 and 3.53. These data may help the researcher as the clinician searching for a cut-off for the NLR, until now lacking.

\section{Additional file}

Additional file 1. Raw data of neutrophil-to-lymphocyte ratio.

\begin{abstract}
Abbreviations
SDs: standard deviations; 95\% Cl: 95\% confidence intervals; P2.5 and P95.5: percentiles 2.5 and $97.5 \%$; NLR: neutrophil-to-lymphocyte ratio.
\end{abstract}

\section{Authors' contributions}

PF, CK, JPD, DL, MDK were involved in study concept and design. MCVP, JPD acquired data. PF, CK and JPD analysed the data. All the authors contributed to the interpretation, the preparation of the manuscript and approved the final version. All authors read and approved the final manuscript.

\footnotetext{
Author details

${ }^{1}$ Department of Anesthesiology, Cliniques Universitaires Saint-Luc, Institute of Neuroscience (pole CEMO), Université Catholique de Louvain, 1200 Brussels, Belgium. ${ }^{2}$ Department of Clinical Biology, Cliniques Universitaires SaintLuc, 1200 Brussels, Belgium. ${ }^{3}$ CESI-Prévention et Protection ASBL, Brussels, Belgium. ${ }^{4}$ Department of Anesthesiology and Perioperative Medicine, Vrije Universiteit Brussel (VUB), Universitair Ziekenhuis Brussel (UZ Brussel), Laarbeeklaan, 101, 1090 Brussels, Belgium.
}

\section{Acknowledgements}

This work was supported by the Departments of Anesthesiology and Clinical Biology Saint-Luc Hospital.

\section{Competing interests}

The authors declare that they have no competing interests.

\section{Availability of data and materials statement}

The data supporting the findings can be found as Additional file.

\section{Ethics and consent to participate}

The analyses were performed with the agreement of the Ethical Committee (ref. 2014/451, Chairperson: Prof. Jean-Marie Maloteaux, av. Hippocrate, 55-14, 1200 Brussels). Considering the analysis as retrospective, given the fact that the samples were pre-collected and treated anonymously, the Ethical Committee gave a waiver for individual consent.

Received: 10 September 2016 Accepted: 10 December 2016 Published online: 03 January 2017

\section{References}

1. Gibson PH, Croal BL, Cuthbertson BH, Small GR, Ifezulike Al, Gibson G, Jeffrey RR, Buchan KG, El-Shafei H, Hillis GS. Preoperative neutrophillymphocyte ratio and outcome from coronary artery bypass grafting. Am Heart J. 2007;154(5):995-1002.

2. Azab B, Chainani V, Shah N, McGinn JT. Neutrophil-lymphocyte ratio as a predictor of major adverse cardiac events among diabetic population: a 4-year follow-up study. Angiology. 2012;64(6):456-65.

3. Hung HY, Chen JS, Yeh CY, Changchien CR, Tang R, Hsieh PS, Tasi WS, You $J F$, You YT, Fan CW, Wang JY, Chiang JM. Effect of preoperative neutrophillymphocyte ratio on the surgical outcomes of stage II colon cancer patients who do not receive adjuvant chemotherapy. Int J Colorectal Dis. 2011;26(8):1059-65

4. Tomita M, Shimizu T, Ayabe T, Yonei A, Onitsuka T. Preoperative neutrophil to lymphocyte ratio as a prognostic predictor after curative resection for non-small cell lung cancer. Anticancer Res. 2011;31(9):2995-8.

5. Sharaiha RZ, Halazun KJ, Mirza F, Port JL, Lee PC, Neugut Al, Altorki NK, Abrams JA. Elevated preoperative neutrophil:Iymphocyte ratio as a predictor of postoperative disease recurrence in esophageal cancer. Ann Surg Oncol. 2011;18(12):3362-9.

6. Kim HS, Han KH, Chung HH, Kim JW, Park NH, Song YS, Kang SB. Neutrophil to lymphocyte ratio for preoperative diagnosis of uterine sarcomas: a case-matched comparison. Eur J Surg Oncol. 2010;36(7):691-8.

7. Garcea G, Ladwa N, Neal CP, Metcalfe MS, Dennison AR, Berry DP. Preoperative neutrophil-to-lymphocyte ratio (NLR) is associated with reduced disease-free survival following curative resection of pancreatic adenocarcinoma. World J Surg. 2011;35(4):868-72.

8. Azab B, Bhatt VR, Phookan J, Murukutla S, Kohn N, Terjanian T, Widmann WD. Usefulness of the neutrophil-to-lymphocyte ratio in predicting short- and long-term mortality in breast cancer patients. Ann Surg Oncol. 2011;19(1):217-24.

9. Keizman D, Ish-Shalom M, Huang P, Eisenberger MA, Pili R, Hammers $H$, Carducci MA. The association of pre-treatment neutrophil to lymphocyte ratio with response rate, progression free survival and overall survival of patients treated with sunitinib for metastatic renal cell carcinoma. Eur J Cancer. 2011;48(2):202-8.

10. Proctor MJ, Morrison DS, Talwar D, Balmer SM, Fletcher CD, O'Reilly DS, Foulis AK, Horgan PG, McMillan DC. A comparison of inflammationbased prognostic scores in patients with cancer. a glasgow inflammation outcome study. Eur J Cancer. 2011;47(17):2633-41.

11. Kahramanca S, Ozgehan G, Seker D, Gökce El, Seker G, Tunç G, Küçükpınar T, Kargıcı H. Neutrophil-to-lymphocyte ratio as a predictor of acute appendicitis. Ulus Travma Acil Cerrahi Derg. 2014;20(1):19-22.

12. Ishizuka M, Shimizu T, Kubota K. Neutrophil-to-lymphocyte ratio has a close association with gangrenous appendicitis in patients undergoing appendectomy. Int Surg. 2012;97(4):299-304. 
13. Walsh SR, Cook EJ, Goulder F, Justin TA, Keeling NJ. Neutrophil-lymphocyte ratio as a prognostic factor in colorectal cancer. J Surg Oncol. 2005;91(3):181-4.

14. Kao S, Pavlakis N, Harvue R, Vardy JL, Boyer MJ, van Zandwijk N, Clarke SJ High blood beutrophil-to-lymphocyte ratio is an indicator of poor prognosis in malignant mesothelioma patients undergoing systemic therapy. Clin Cancer Res. 2010;16(23):5805-13.
15. Cho HB, Hur HW, Kim SWU, Kim SH, Kim JH, Kim YT, Lee K. Pre-treatment neutrophil to lymphocyte ratio is elevated in epithelial ovarian cancer and predicts survival after treatment. Cancer Immunol Immunother. 2009;58(1):15-23.

16. Katayev A, Balciza C, Seccombe DW. Establishing reference intervals for clinical laboratory test results. Is there a better way? Am J Clin Pathol. 2010;133(2):180-6.

\section{Submit your next manuscript to BioMed Central and we will help you at every step:}

- We accept pre-submission inquiries

- Our selector tool helps you to find the most relevant journal

- We provide round the clock customer support

- Convenient online submission

- Thorough peer review

- Inclusion in PubMed and all major indexing services

- Maximum visibility for your research

Submit your manuscript at

www.biomedcentral.com/submit 